Short communication

\title{
More than 500 million Chinese urban residents (14\% of the global urban population) are imperiled by fine particulate hazard ${ }^{\text {th }}$
}

\author{
Chunyang He ${ }^{\text {a, }}{ }^{* *}$, Lijian Han ${ }^{\text {b, }}{ }^{*}$, Robin Q. Zhang ${ }^{c}$ \\ ${ }^{a}$ Center for Human-Environment System Sustainability (CHESS), State Key Laboratory of Earth Surface Processes and Resource Ecology (ESPRE), Beijing \\ Normal University, Beijing 100875, China \\ b State Key Laboratory of Urban and Regional Ecology, Research Center for Eco-Environmental Sciences, Chinese Academy of Sciences, Beijing 100085, China \\ ${ }^{\mathrm{c}}$ Department of Geosciences, Murray State University, Murray, KY 42071, USA
}

\section{A R T I C L E I N F O}

\section{Article history:}

Received 30 May 2016

Received in revised form

15 July 2016

Accepted 18 July 2016

Available online 3 August 2016

\section{Keywords:}

Air pollution

Environmental sustainability

Developing country

Population migration

\begin{abstract}
A B S T R A C T
China's urbanization and the subsequent public vulnerability to degenerated environment is important to global public health. Among the environmental problems, fine particulate $\left(\mathrm{PM}_{2.5}\right)$ pollution has become a serious hazard in rapidly urbanizing China. However, quantitative information remains inadequate. We thus collected $\mathrm{PM}_{2.5}$ concentrations and population census records, to illustrate the spatial patterns and changes in the $\mathrm{PM}_{2.5}$ hazard levels in China, and to quantify public vulnerability to the hazard during 2000-2010, following the air quality standards of World Health Organization. We found that $28 \%$ ( 2.72 million $\mathrm{km}^{2}$ ) of China's territory, including $78 \%$ of cities ( 154 cities) with a population of $>1$ million, was exposed to $\mathrm{PM}_{2.5}$ hazard in 2010; a $15 \%$ increase $\left(1.47\right.$ million $\left.\mathrm{km}^{2}\right)$ from 2000 to 2010. The hazards potentially impacted the health of $72 \%$ of the total population (942 million) in 2010 , including $70 \%$ of the young ( 206 million) and $76 \%$ of the old (71 million). This was a significant increase from the $42 \%$ of total the population ( 279 million) exposed in 2000 . Of the total urban residents, $76 \%$ (501 million) were affected in 2010. Along with $\mathrm{PM}_{2.5}$ concentration increase, massive number of rural to urban migration also contributed greatly to China's urban public health vulnerability.
\end{abstract}

(c) 2016 Elsevier Ltd. All rights reserved.

\section{Introduction}

China's urbanization and the subsequent public vulnerability to degenerated environmental conditions is important to global public health, because China's urbanized population is projected to account for almost $12 \%$ of the global urban population increase by 2050 (World urbanization prospects, 2014). Since the start of the "Reform and Opening-up" policy in the late 1970s, China's economy and accompanying urbanization have been growing at an unprecedented rate (Huang et al., 2014; Seinfeld, 2014). This rapid growth in a short period has led to improvements in living standards, but has also caused severe environmental pollution in areas of intense human activity (Gong et al., 2012). Especially, the heavy fine particulate $\left(\mathrm{PM}_{2.5}\right)$ pollution has already caused heavy haze and

\footnotetext{
This paper has been recommended for acceptance by David Carpenter.

* Corresponding author.

** Corresponding author

E-mail addresses: hcy@bnu.edu.cn (C. He), ljhan@rcees.ac.cn (L. Han), qzhang@ murraystate.edu (R.Q. Zhang).
}

increased risk to public health in densely populated areas of China (Bai et al., 2014; Han et al., 2015). Only 24 of the 350 prefectures in China had annual $\mathrm{PM}_{2.5}$ concentrations within the World Health Organization (WHO) air quality guidelines (AQG; $10 \mu \mathrm{g} / \mathrm{m}^{3}$ ), whereas 165 prefectures had annual $\mathrm{PM}_{2.5}$ concentrations higher than the WHO Interim Target-1 (IT- $1 ; 35 \mu \mathrm{g} / \mathrm{m}^{3}$ ) based on annual averaged measurements during 2001-2006 (Han et al., 2014). These areas of high $\mathrm{PM}_{2.5}$ concentrations are mainly located in the east of China with a rapid increase in both the areas of high concentrations and the number of cities influenced, potentially impacting the health of the population (Gong et al., 2012; Hyslop, 2009; Lim et al., 2012). However, quantitative information remains inadequate despite its crucial importance to sustainable urban development in China. Therefore, we collected remote sensing data on $\mathrm{PM}_{2.5}$ concentrations (Boys et al., 2014; Van Donkelaar et al., 2015) and population census record, to illustrate the spatial patterns and changes in the $\mathrm{PM}_{2.5}$ hazard levels in China, and to quantify public vulnerability to the $\mathrm{PM}_{2.5}$ hazard during 2000-2010, following the air quality standards of WHO. 


\section{Materials and methods}

\subsection{Materials}

$\mathrm{PM}_{2.5}$ concentration data:We used remote sensing to estimate $\mathrm{PM}_{2.5}$ concentrations. An optimal estimation algorithm based on top-of-atmosphere reflectance observed by Moderate Resolution Imaging Spectroradiometer (MODIS) was developed to produce the $\mathrm{PM}_{2.5}$ concentration data used in the present study (Boys et al., 2014; Van Donkelaar et al., 2010). Using a simulation of the GEOS-Chem chemical transport model, $\mathrm{PM}_{2.5}$ concentrations were estimated from a combination of MODIS and Multi-angle Imaging SpectroRadiometer (MISR) aerosol optical depth (AOD) data with aerosol vertical profiles and scattering properties (Van Donkelaar et al., 2010; Van Donkelaar et al., 2013). The global $\mathrm{PM}_{2.5}$ concentration dataset had a spatial resolution of $10 \mathrm{~km}$ as a 3-year moving average, which was applied to reduce the uncertainty of the annual
$\mathrm{PM}_{2.5}$ concentration, during 1999-2011 (11; Available at: http:// fizz.phys.dal.ca/ atmos/martin/). Moreover, the dataset was validated with ground measurement at global scale, and then significant agreement between satellite-derived estimates and ground measurements in China, outside North America and Europe, was obtained $(r=0.81$, slope $=0.68$ ) (Van Donkelaar et al., 2015; Van Donkelaar et al., 2010; Van Donkelaar et al., 2013). It thus provided an extensive and reasonable $\mathrm{PM}_{2.5}$ concentration dataset for our study at a large regional scale. In the present study, we used a subset of the global $\mathrm{PM}_{2.5}$ concentration dataset that covered China in 2000 and 2010.

Population records:The population records for 2000 and 2010 were obtained from the national population census reported by the National Bureau of Statistics of the People's Republic of China (available at http://www.stats.gov.cn/tjsj/pcsj/), and we used the total, young (age $<14$ years), old (age $>64$ years), urban, and rural populations of each prefecture.

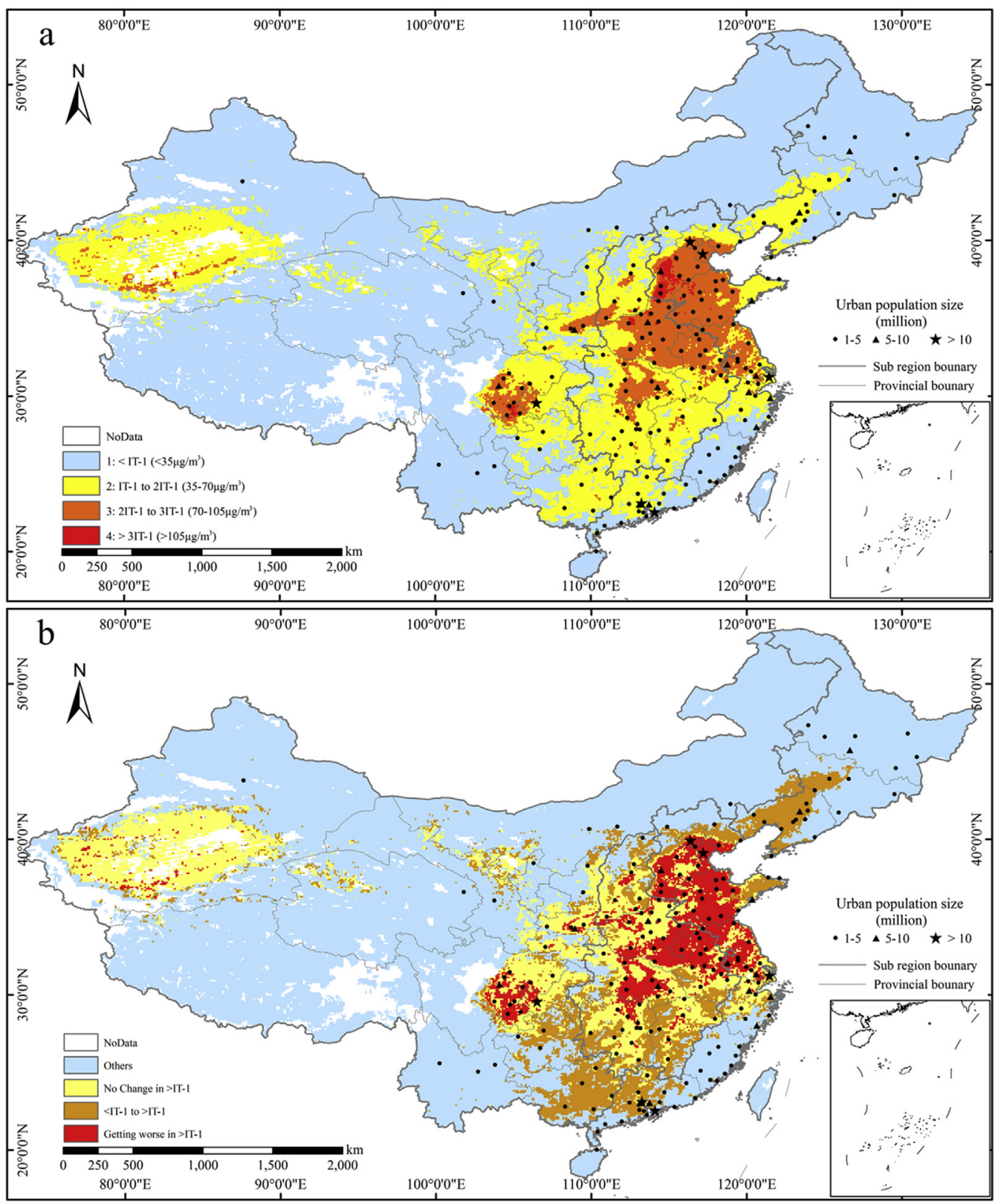

Fig. 1. Fine particulate hazard in 2010 (a) and changes in its distribution between 2000 and 2010 (b). 
Urban distribution, prefecture and province boundaries, and the regionalization system of China:We used China's urban distribution, which is the impervious surface area that observed with remote sensing technology, with a spatial resolution of $1 \mathrm{~km}$ to separate urban from non-urban areas for each prefecture in 2000 and 2010 (Liu et al., 2012). Prefecture and province boundaries at 1:250,000 scale were obtained from the National Geomatics Center of China (http://ngcc.sbsm.gov.cn/). We adopted China's most widely accepted regionalization system for the mainland: East China is the most developed area that covers Beijing, Tianjin, the Shanghai Municipalities, and Hebei, Shandong, Jiangsu, Zhejiang, Fujian, Guangdong, and Hainan Provinces; Northeast China is a traditional industrial base that covers Liaoning, Jilin and Heilongjiang Provinces; Central China is a slowly developing area that covers Shanxi, Henan, Anhui, Jiangxi, Hubei and Hunan Provinces; and West China is the least developed area that covers Chongqing Municipality, Sichuan, Guizhou, Yunnan, Shaanxi, Gansu, and Qinghai Provinces, Guangxi, Ningxia, Inner Mongolia, and the Tibet Autonomous Region (the Taiwan-Hong Kong-Macao region was not considered in this study) (Supplementary materials 4).

\subsection{Methodology}

Urban $\mathrm{PM}_{2.5}$ concentrations: The mean $\mathrm{PM}_{2.5}$ concentrations in urban areas were calculated based on China's urban distribution map and the China subset of the global $\mathrm{PM}_{2.5}$ concentrations dataset for each prefecture in both 2000 and 2010 (Han et al., 2014). To render the urban $\mathrm{PM}_{2.5}$ concentrations comparable between 2000 and 2010, we superimposed the urban distribution maps of 2000 and 2010 to obtain the urban and rural areas that remained constant. The $\mathrm{PM}_{2.5}$ concentrations in the urban areas were then calculated based on the $\mathrm{PM}_{2.5}$ concentration dataset and these persistent urban areas.

$\mathrm{PM}_{2.5}$ hazard levels: Because China has a high level of $\mathrm{PM}_{2.5}$ pollution, using the air quality guideline of World Health Organization (WHO) is not sufficient to illustrate the conditions in China. We therefore use the WHO's interim target-1 (IT-1, $35 \mu \mathrm{g} / \mathrm{m}^{3}$ ), two fold the IT-1 (2IT-1, $\left.70 \mu \mathrm{g} / \mathrm{m}^{3}\right)$, and three fold the IT-1 (3IT-1, $105 \mu \mathrm{g} /$ $\mathrm{m}^{3}$ ) as the standards to quantify the $\mathrm{PM}_{2.5}$ hazard levels and public vulnerability to $\mathrm{PM}_{2.5}$ hazards.

Exposure analysis: The urban $\mathrm{PM}_{2.5}$ concentration data along with the urban population records for each prefecture were used to calculate the urban population exposed to high air pollution levels, with $\mathrm{PM}_{2.5}$ concentrations higher than the WHO's IT-1 $\left(35 \mu \mathrm{g} / \mathrm{m}^{3}\right)$ in 2000 and 2010.

\section{Result and discussion}

We found that China's average $\mathrm{PM}_{2.5}$ concentration $\left(28.7 \mu \mathrm{g} / \mathrm{m}^{3}\right)$ was more than twice the global average $\left(11.8 \mu \mathrm{g} / \mathrm{m}^{3}\right)$ in 2010 , and the increase in $\mathrm{PM}_{2.5}$ concentration $\left(5.6 \mu \mathrm{g} / \mathrm{m}^{3}\right)$ between 2000 and 2010 was nearly eightfold greater than the global average increase $\left(0.7 \mu \mathrm{g} / \mathrm{m}^{3}\right)$ (Supplementary materials 1$)$. In 2010, 28\% of China's territory (2.72 million $\mathrm{km}^{2}$ ) was exposed to high $\mathrm{PM}_{2.5}$ hazard levels, including $21 \%$ (2.04 million $\mathrm{km}^{2}$ ) exposed to $\mathrm{PM}_{2.5}$ hazard levels of IT- 1 to twofold IT-1 (2IT-1), 7\% (0.64 million $\left.\mathrm{km}^{2}\right)$ exposed to $\mathrm{PM}_{2.5}$ hazard levels of 2IT-1 to threefold IT-1 (3IT-1), and $0.4 \%$ (0.04 million $\mathrm{km}^{2}$ ) exposed to $\mathrm{PM}_{2.5}$ hazard levels of more than threefold IT-1 (>3IT-1). The high PM 2.5 hazard levels were primarily observed in the East China Plain, including Beijing, Tianjin, south Hebei province, Henan province, Shandong province, and north Anhui and Jiangsu provinces (Fig. 1a). Such large areas with high

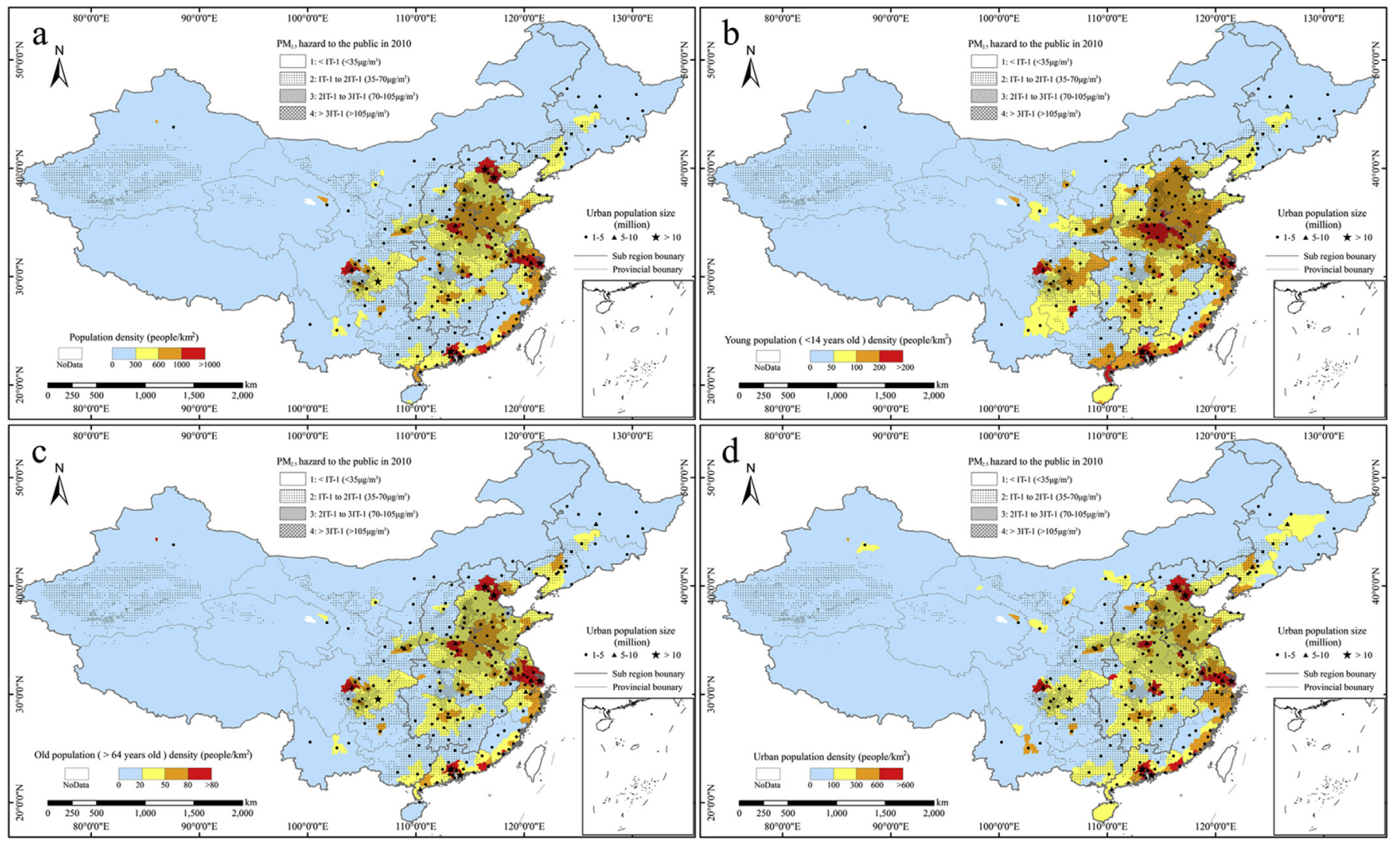

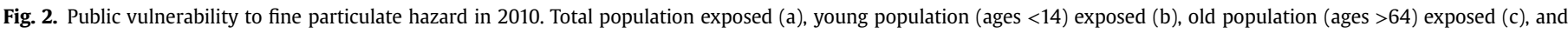
urban population exposed (d). 
$\mathrm{PM}_{2.5}$ hazard levels represent a significant increase during 2000-2010. More than $15 \%$ of China's territory ( 1.47 million $\mathrm{km}^{2}$ ) showed increased $\mathrm{PM}_{2.5}$ concentrations, including $10 \%$ of China's territory changing from $<\mathrm{IT}-1$ to $>$ IT -1 and $6 \%$ of China's territory with >IT-1 levels in 2000 worsening by 2010. The deteriorating areas were mainly located in Beijing, Tianjin, southern Hebei Province, and central and western Shandong Province. The newly added areas exposed to $\mathrm{PM}_{2.5}$ hazard that changed from $<$ IT- 1 to $>$ IT-1 were mainly found in west Liaoning province, east Shandong province, Guangdong and Guangxi provinces (Fig. 1b). In 2010, 78\% of large cities with populations greater than 1 million (154 cities) were exposed to high $\mathrm{PM}_{2.5}$ hazard levels, including 38\% (76 cities), $35 \%$ ( 70 cities), and $4 \%$ ( 8 cities) with $\mathrm{PM}_{2.5}$ hazard levels of IT- 1 to 2IT-1, 2IT-1 to 3IT-1, and >3IT-1, respectively. Eight cities in East and Central China were exposed to the highest $\mathrm{PM}_{2.5}$ hazard levels of >3IT-1: Shijiazhuang, Xingtai, and Handan in Hebei province and Heze in Shandong province in East China, and Zhengzhou, Luoyang, Anyang, and Kaifeng in Henan province in Central China. All six large cities with a population greater than 10 million (Beijing, Shanghai, Tianjin, Chongqing, Guangzhou, and Shenzhen) were exposed to high $\mathrm{PM}_{2.5}$ hazard levels (>IT-1).

We also found that the heavy $\mathrm{PM}_{2.5}$ hazards have already impacted the health of Chinese population (Fig. 2a). In 2010, 72\% of the total population (942 million) was exposed to the high $\mathrm{PM}_{2.5}$ hazard levels, mainly those living in East (29\% of the total population, 378 million) and Central China (26\% of the total population, 341 million). Some research findings suggested that old and young members of the population are more susceptible, showing increased hospitalization and mortality (Gouveia and Fletcher, 2000; Brunekreef and Holgate, 2002). In addition, we discovered that $70 \%$ of the young population (ages $<14$; 206 million) were exposed to the high $\mathrm{PM}_{2.5}$ hazard levels, including 72 million in East China, 83 million in Central China, and 44 million in West China. The main area of impact for the young population is in the East China Plain, with the largest effect in the northern part of Henan province (Fig. 2b). Furthermore, $76 \%$ of the old population (ages

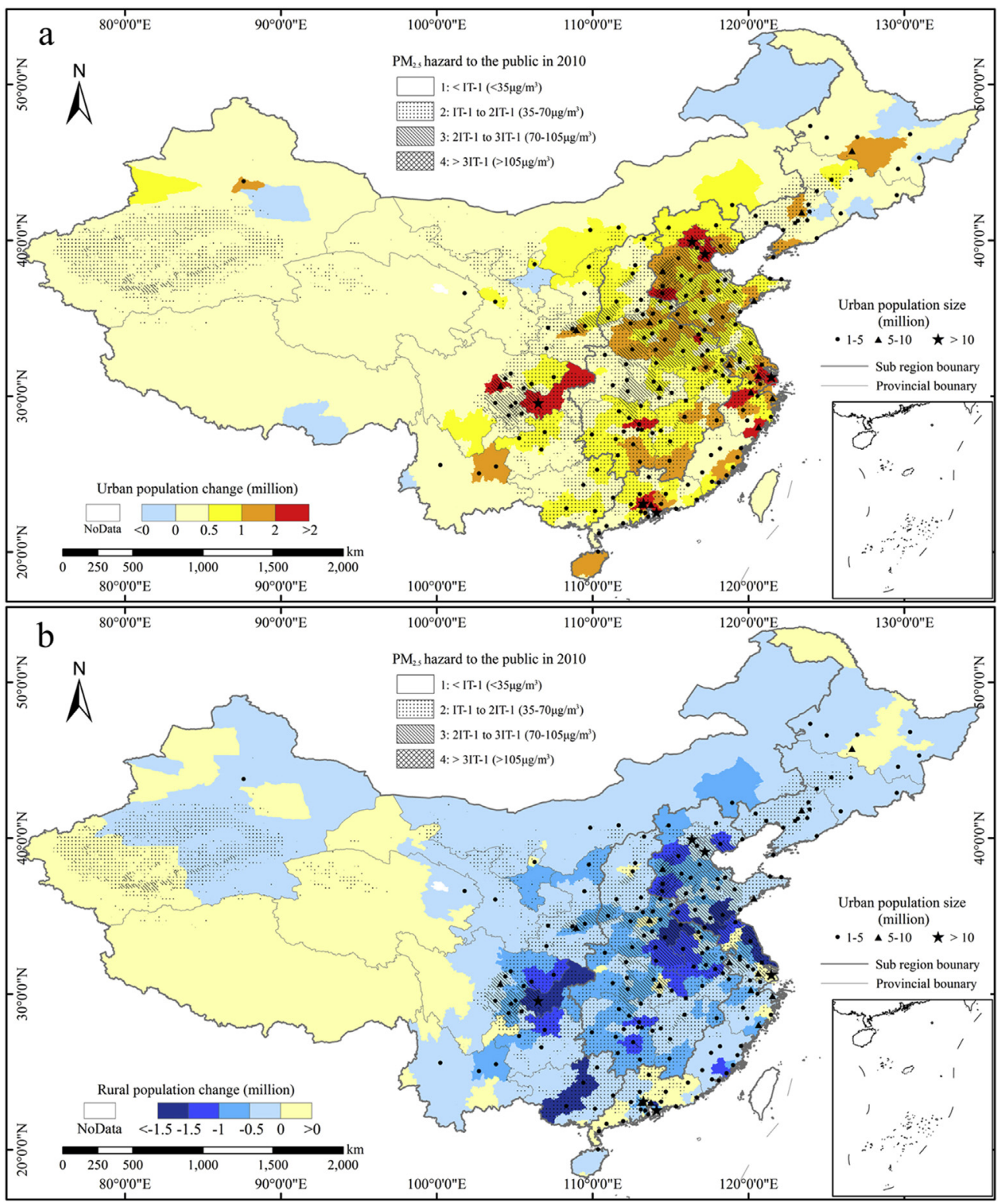

Fig. 3. Urban (a) and rural (b) population changes between 2000 and 2010. 
$>64 ; 71$ million) were exposed to the high $\mathrm{PM}_{2.5}$ hazard levels, including 31 million in East China, 24 million in Central China, and 13 million in West China. The exposed seniors were densely distributed in the East China Plain. Six large cities, Shanghai, Beijing, Tianjin, and Suzhou in East China, Chongqing and Chengdu in West China, accounted for $14 \%$ ( 10 million) of the affected seniors (Fig. 2c). The rapid increase of $21 \%$ total population ( 279 million) between 2000 and 2010 contributed to this rapid increase in public vulnerability to increased $\mathrm{PM}_{2.5}$ hazard. From 2000 to 2010, we found a further 97 million of the young population became vulnerable. Thirty-four million young people in East China, 37 million in Central China, and 18 million in West China experienced increased exposure. Eight million more seniors have been exposed between 2000 and 2010, including increases of six million, three million, and one million in East, Northeast and Central China, and a decrease of two million in West China.

We also investigated the vulnerability of the urban population to $\mathrm{PM}_{2.5}$ hazard. We found that $76 \%$ of the total urban population (501 million) was affected by the $\mathrm{PM}_{2.5}$ hazard in 2010 (Fig. 2d), with 237million in East China and 149 million in Central China. Moreover, five large cities (Shanghai, Beijing, Chongqing, Tianjin, and Guangzhou) accounted for 15\% (73 million) of the total affected urban population in 2010 . We found a notable increase of $21 \%$ of the urban population (278 million) exposed to $\mathrm{PM}_{2.5}$ hazard between 2000 and 2010. Moreover, population increases in large cities contributed a large proportion to the exposed urban population. For instance, $15 \%$ ( 51 cities) of large cities with a population $>1$ million accounted for $35 \%$ of the total increase (97 million) in the urban population subjected to increased health risks due to $\mathrm{PM}_{2.5}$ hazard in China. The population of five megacities with a population $>10$ million (Beijing, Shanghai, Guangzhou, Tianjin, and Chongqing) accounted for $8 \%$ of the total increased urban population (23 million) exposed to $\mathrm{PM}_{2.5}$ hazard.

Urbanization is considered as one of the engines of modernization and economic growth, and is serving an important role in achieving China's urban dream (Bai et al., 2014). In March 2014, the Chinese central government released the National New-type Urbanization Plan, which sets targets for the proportion of China's urban population to rise from $52 \%$ in 2012 to $60 \%$ by 2020 (Bai et al., 2014). However, along with the increase in $\mathrm{PM}_{2.5}$ concentrations, we found that mass population migration induced by rapid urbanization also contributed extensively to urban public health vulnerability in China. Rural population decreased by 116 million while urban population increased by 210 million from 2000 to 2010. The change was particularly significant in East and Central China (Fig. 3a, b). In areas with $\mathrm{PM}_{2.5}$ hazard in 2010, we estimated that $2-21 \%$ of the increased urban population that affected by $\mathrm{PM}_{2.5}$ hazard was the result of natural urban population increase, but $79-98 \%$ of the increase was attributed to rural-to-urban migration (Supplementary Materials 2). Meanwhile, the affected rural population decreased by 101 million, from 585 million in 2000 to 484 million in 2010. In megacities such as Beijing, Shanghai, Tianjin, and Chongqing, the urban population increased from three to six million (Supplementary Materials 3). The vast majority of the rural population decrease resulted from migration to urban areas was induced by rapid urbanization. This differs from the previous perception that most of the increase in hazard exposure was driven by increases in $\mathrm{PM}_{2.5}$ concentration rather than changes in population due to migration (Van Donkelaar et al., 2015).

We argue that both the Chinese government and the public should pay more attention to environmental protection as rapid urbanization progresses over the next decade. We suggest that the control and reduction of air pollutant emission in megacities in East and Central China should be implemented rapidly and effectively. We urge that the active participation of the public in reducing air pollution as urbanization progresses should be further encouraged and supported. We believe that the "Win-win" cooperation of the government and the public to mitigate the $\mathrm{PM}_{2.5}$ hazard would ensure a sustainable future while accomplishing China's dream of urbanization.

\section{Acknowledgements}

The research was a part of projects supported by National Natural Science Foundation of China (Grant Number: 41321001, 41222003, and 41301199).

\section{Appendix A. Supplementary data}

Supplementary data related to this article can be found at http:// dx.doi.org/10.1016/j.envpol.2016.07.038.

\section{References}

Bai, X., Shi, P., Liu, Y., 2014. Realizing China's urban dream. Nature 509, 158-160. Boys, B., et al., 2014. Fifteen-year global time series of satellite-derived fine particulate matter. Environ. Sci. Technol. 48, 11109-11118.

Brunekreef, B., Holgate, S., 2002. Air pollution and health. Lancet 360, 1233-1242. Gong, P., et al., 2012. Urbanization and health in China. Lancet 379, 843-851.

Gouveia, N., Fletcher, T., 2000. Time series analysis of air pollution and mortality: effects by cause, age and socioeconomic status. J. Epidemiol. Commun. H. 54 $750-755$.

Han, L., Zhou, W., Li, W., Li, L., 2014. Impact of urbanization level on urban air quality: a case of fine particles $\left(\mathrm{PM}_{2.5}\right)$ in Chinese cities. Environ. Pollut. 194, $163-170$.

Han, L., Zhou, W., Li, W., 2014. City as a major source area of fine particulate $\left(\mathrm{PM}_{2.5}\right)$ in China. Environ. Pollut. 206, 183-187.

Huang, R., et al., 2014. High secondary aerosol contribution to particulate pollution during haze events in China. Nature 514, 218-222.

Hyslop, N., 2009. Impaired visibility: the air pollution people see. Atmos. Environ. 43, 182-195.

Lim, S., et al., 2012. A comparative risk assessment of burden of disease and injury attributable to 67 risk factors and risk factor clusters in 21 regions, 1990-2010: a systematic analysis for the Global Burden of Disease Study 2010. Lancet 380, 2224-2260.

Liu, J., Zhao, Q., Hu, Y., 2012. Regional differences in China's urban expansion from the late 20th to early 21 st century based on remote sensing information. Chin. Geogr. Sci. 22, 1-14.

Seinfeld, J., 2014. Air pollution: a half century of progress. AICHE J. 50, 1096-1108. Van Donkelaar, A., et al., 2010. Global estimates of ambient fine particulate matter concentrations from satellite-based aerosol optical depth: development and application. Environ. Health Perspect. 118, 847-855.

Van Donkelaar, A., et al., 2013. Optimal estimation for global ground-level fine particulate matter concentrations. J. Geophys. Res. Atmos. 118, 5621-5636.

Van Donkelaar, A., Martin, R., Brauer, M., Boys, B., 2015. Use of satellite observation for long-term exposure assessment of global concentration of fine particulate matter. Environ. Health Perspect. 123, 135-143.

World urbanization prospects, Jul. 2014. The 2014 Revision. Department of Economic and Social Affairs, United Nations, New York. 